\title{
Heifer Fertility in Norwegian Dairy Cattle: Variance Components and Genetic Change
}

\author{
I. M. A.-Ranberg, ${ }^{\star} \dagger$ B. Heringstad, ${ }^{*}$ G. Klemetsdal, ${ }^{*}$ M. Svendsen, $†$ and T. Steine† \\ ${ }^{*}$ Department of Animal Science, Agricultural University of Norway, Box 5025, N-1432 Ås, Norway \\ †GENO Breeding and A.I. Association, Box 5025, N-1432 Ås, Norway
}

\begin{abstract}
Variance components and genetic change were estimated for 56-d nonreturn rate in virgin heifers using first insemination records of a total of $1,632,961$ Norwegian Dairy Cattle daughters of 2945 sires. Six univariate mixed linear sire models were compared. The heritabilities varied from $1.2 \%$ to $1.4 \%$. All models gave favorable, although different, estimates of genetic change of 56-d nonreturn rate. The method used to validate the genetic trend did not detect bias in any of the models. Goodness-of-fit and predictive ability were used to further validate the models. Three models included service sire, but this effect had little influence on the results. Models treating the herd-year effects as random showed smaller prediction error and higher correlation between observed and predicted values than the models treating herd-year effect as fixed. To avoid confounding of environmental and genetic effects, the model including fixed effect of month-year was preferred over a model with only month of first insemination to estimate the genetic change. Female fertility has been successfully included in the total merit index of Norwegian Dairy Cattle for $20 \mathrm{yr}$. This has resulted in genetic improvement and the chosen model showed annual genetic change of $0.04 \%$ for 56 -d nonreturn rate in heifers between 1979 and 2000 .
\end{abstract}

(Key words: female fertility, nonreturn rate, variance components, genetic change)

Abbreviation key: $\mathbf{M S E}=$ mean squared error, $\mathbf{N R F}$ $=$ Norwegian Dairy Cattle, NR56D0 $=56$ - $d$ nonreturn rate in virgin heifers.

\section{INTRODUCTION}

In dairy cattle, female reproduction problems lead to prolonged calving intervals, increased insemination and veterinary costs, higher culling rates, and thus

Received November 29, 2002.

Accepted February 23, 2003.

Corresponding author: I. M. A.-Ranberg; e-mail: ina.ranberg@ihf. nlh.no. increased replacement costs. Several studies using field data (Janson and Andreasson, 1981; Hansen et al., 1983; Lyons and Freeman, 1991; Hoekstra et al., 1994; Weller and Ezra, 1997; Roxström et al., 2001) found unfavorable genetic correlations between milk yield and female fertility traits. Genetic deterioration of female fertility is therefore expected as a result of longterm single trait selection for increased milk production. To counteract such undesirable correlated response to selection, female fertility needs to be observed on large daughter groups and properly weighted in the total merit index. In Sweden, the fertility index includes fertility in both heifers and first lactation cows. Based on this fertility index, Lindhé and Philipson (2001) found that the genetic level of female fertility in Swedish Red and White was stable from 1985 to 2000, while fertility in Swedish Friesian (SLB) decreased during that period. They suggested that this was caused by heavy influence from imported Holstein semen in SLB.

The female fertility trait, nonreturn rate in virgin heifers, has been selected for in Norwegian Dairy Cattle (NRF) since 1972. The trait has received considerable weight in the total merit index for sires (8\% to $15 \%$ ) over the entire period. Documentation of the effect of long-term selection for improved female fertility is therefore possible in NRF.

The outcome of an insemination depends on both female and male fertility. Maternal effects include the female ability to produce fertile eggs and further to develop the embryo into a viable calf. Direct effects can be partitioned into the effect of transmitting genes from service sire and cow to the embryo and quality of the semen. In France, Boichard and Manfredi (1994) found that the service sire contributed $0.8 \%$ of the total phenotypic variance for conception rate. Weigel and Rekaya (2000) reported linear model repeatability estimates for service sire effect on 60 -d nonreturn rate between $0.3 \%$ and $0.5 \%$.

The aims of this study were to investigate the quality of Norwegian fertility data and to validate alternative models to be used for estimating variance components and genetic change of 56-d nonreturn rate (NR56D0) in NRF virgin heifers. 


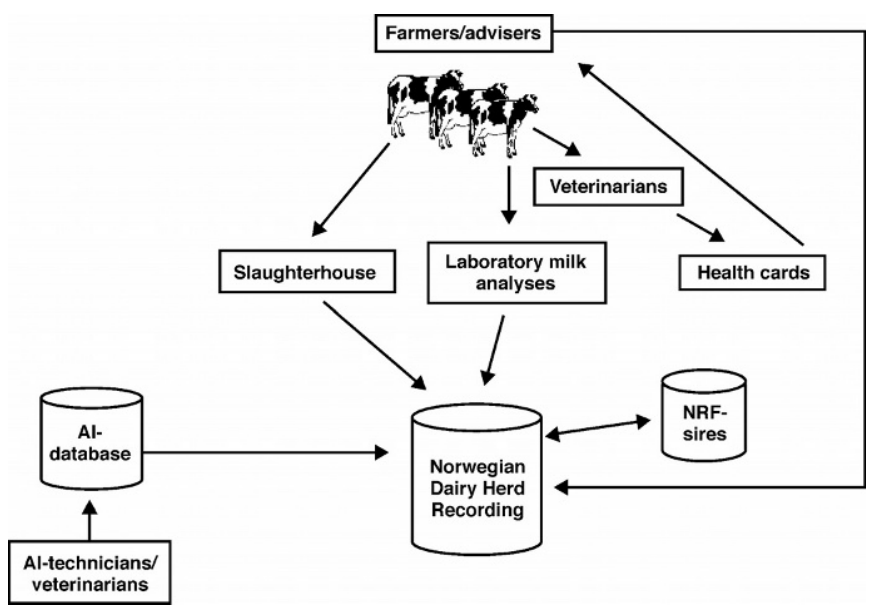

Figure 1. Data flow in the Norwegian Dairy Herd Recording System.

\section{MATERIALS AND METHODS}

\section{Data}

The dairy farmers co-operative, TINE BA, has been responsible for the Norwegian Dairy Herd Recording System since 1978. This databank includes information from several sources: insemination reports, health cards, slaughterhouses, laboratory milk analyses, advisers and farmers and is linked to the database of NRF-sires (Figure 1). All animals recorded since September 1, 1978, can be accessed in a database at the Department of Animal Science, Agricultural University of Norway as described by Heringstad et al. (1999a). In $2001,95.4 \%$ of Norwegian cows and $91.9 \%$ of all herds were registered in the Norwegian Dairy Herd Recording System (TINE, 2002). Each year, an average of about $38 \%$ of the cows are bred by NRF test sires and the number of daughters per test sire varies between 250 and 300 .

AI-technicians and veterinarians report all inseminations into the AI-database, and they are paid by GENO (Norwegian Breeding and AI-Association) when the inseminations are registered. From the AI-database, re- corded inseminations are transferred and stored in the Norwegian Dairy Herd Recording System. Currently, only 31 farmers (GENO, 2002) carry out inseminations in their own herds. These farmers report their inseminations into the AI-database.

Records of a total of 2,183,618 first inseminations in the period from September 1, 1978, to December 1, 2000 , were available for this study. All first and second crop daughters (with first insemination in the period) of sires that were progeny tested after 1980 were included. Both the sire and service sire had to be present in the sire pedigree file, and a record was accepted if age at first insemination was between 10 and $31 \mathrm{mo}$. Records were discarded if the heifer was treated by a veterinarian for reproductive disorders or was culled within 56 $\mathrm{d}$ after first insemination. Double insemination was defined as a new insemination occurring within 0 to $5 \mathrm{~d}$, and the records were excluded if different sires were used in a double insemination. The data editing process is described in Table 1. Data used in the analysis contained 1,632,961 records from daughters of 2945 sires. A total of 3163 service sires were represented in the data. A sire pedigree file was built by tracing the pedigree of sires of heifers and service sires back as many generations as possible. A total of 3532 males, the oldest were born in 1940, were included in the pedigree file.

The trait NR56D0 was defined as binary, based on whether or not the heifer had a second insemination within $56 \mathrm{~d}$ after first insemination. The nonreturn rate was based on first inseminations only. In the analyzed data, NR56D0 was $74.6 \%$, and $6.5 \%$ of the heifers had double inseminations. Summary statistics of the analyzed data are given in Table 2, and Figure 2 depicts yearly average NR56D0 from 1979 to 1999 . The years 1978 and 2000 were only partially represented and therefore excluded from Figure 2. Phenotypically, the averages of NR56D0 increased from $72.5 \%$ in 1979 to $75.9 \%$ in 1999.

One possible problem when using nonreturn rate as a measure of fertility is that not all natural services may be reported. The definition of NR56D0 implies that heifers are assumed pregnant if there is no recorded

Table 1. Data editing and number of records in the analysis.

\begin{tabular}{lc}
\hline Total no. of records & $2,183,618$ \\
No. of records in the analysis & $1,632,961$ \\
\hline Reason for discarding a record: & Records discarded (\% of total) \\
-Sire of the heifer unknown or not in the pedigree file & 16.8 \\
- Heifer with reproductive veterinary treatments & 0.6 \\
-Natural service as first mating & 2.9 \\
-Culled within 56 d after first insemination & 0.4 \\
-Age at first insemination outside 10 to 31 mo & 0.8 \\
-Two different service sires used in double insemination & 1.6 \\
-Service sire not present in the pedigree file & 2.1 \\
\hline
\end{tabular}


Table 2. Summary statistics of data used for analyses of 56-d nonreturn rate (NR56D0) in virgin heifers.

\begin{tabular}{lr}
\hline Sires, no. & \\
Heifers (daughters) per sire, mean no. & 2945 \\
Service sires, no. & 554 \\
Heifers per service sire, mean no. & 5163 \\
Herd-year classes, no. & 387,129 \\
Records per herd-year class, mean no. & 4.2 \\
Double inseminations, \% & 6.5 \\
NR56D0, \% & 74.6 \\
Insemination, year & $1978-2000$ \\
\hline
\end{tabular}

breeding within $56 \mathrm{~d}$ after first insemination. This is not always true, although NR56D0 is less influenced by the farmer decisions than other fertility traits. If data were restricted to heifers that had only one insemination and first calving reported, $52.5 \%$ of the data would remain. This subset can be used to test reporting of natural services. The proportion of heifers with a prolonged interval from insemination to calving is depicted in Figure 3 and shows that heifers with interval from insemination to calving longer than 295 varied between $1.7 \%$ and $2.7 \%$. There was no trend indicating changes in the reporting of natural services over time.

\section{Models}

Six univariate mixed linear sire models were used to estimate variance components and predicted transmitting ability (PTA):

Model 1:

$$
\mathrm{Y}_{\mathrm{ijklmno}}=\mathrm{A}_{\mathrm{i}}+\mathrm{M}_{\mathrm{j}}+\mathrm{DI}_{\mathrm{k}}+\mathrm{hy}_{\mathrm{l}}+\mathrm{s}_{\mathrm{m}}+\mathrm{Ss}_{\mathrm{n}}+\mathrm{e}_{\mathrm{ijklmnno}}
$$

where

$$
\begin{aligned}
\mathrm{Y}_{\mathrm{ijklmno}}= & \text { observation of } 56-\mathrm{d} \text { nonreturn }(0=\text { return, } 1 \\
& =\text { nonreturn }) \text { of heifer } 0
\end{aligned}
$$

$\mathrm{A}_{\mathrm{i}}=$ fixed effect of age $i$ at first insemination, in weeks, with 92 classes ranging from 10 to 31 mo of age;

$\mathrm{M}_{\mathrm{j}}=$ fixed effect of calendar month $j$ at first insemination in 12 classes;

$\mathrm{DI}_{\mathrm{k}}=$ fixed effect of double insemination $k$ in 2 classes;

$\mathrm{hy}_{\mathrm{l}}=$ random effect of herd-year $l$;

$\mathrm{s}_{\mathrm{m}}=$ random effect of sire $m$;

$\mathrm{SS}_{\mathrm{n}}=$ random effect of service sire $n$; and

$\mathrm{e}_{\mathrm{ijk} \mathrm{kmno}}=$ random residual term .

Model 2:

$$
\mathrm{Y}_{\mathrm{ijklmno}}=\mathrm{A}_{\mathrm{i}}+\mathrm{M}_{\mathrm{j}}+\mathrm{DI}_{\mathrm{k}}+\mathrm{HY}_{\mathrm{l}}+\mathrm{s}_{\mathrm{m}}+\mathrm{SS}_{\mathrm{n}}+\mathrm{e}_{\mathrm{ijklmnno}}
$$

where

$$
\begin{aligned}
\mathrm{HY}_{1} & =\text { fixed effect of herd-year class } l \text { (replacing hy } \\
& \text { in [1]); and other terms defined in [1]. }
\end{aligned}
$$

Model 3:

$$
\mathrm{Y}_{\mathrm{ijk} l m n o}=\mathrm{A}_{\mathrm{i}}+\mathrm{MY}_{\mathrm{j}}+\mathrm{DI}_{\mathrm{k}}+\mathrm{hy}_{\mathrm{l}}+\mathrm{s}_{\mathrm{m}}+\mathrm{Ss}_{\mathrm{n}}+\mathrm{e}_{\mathrm{ijkl} \mathrm{lmnno}}
$$

where

$$
\begin{aligned}
\mathrm{MY}_{\mathrm{j}}= & \text { fixed effect of month-year class in } 266 \text { classes } \\
& \text { (replacing } \mathrm{M}_{\mathrm{j}} \text { in [1]); and other terms as de- } \\
& \text { fined in [1]. }
\end{aligned}
$$

Models 4, 5, and 6 were similar to Models 1, 2, and 3, respectively, but without the effect of service sire.

The following (co)variance structures were assumed for the random effects:

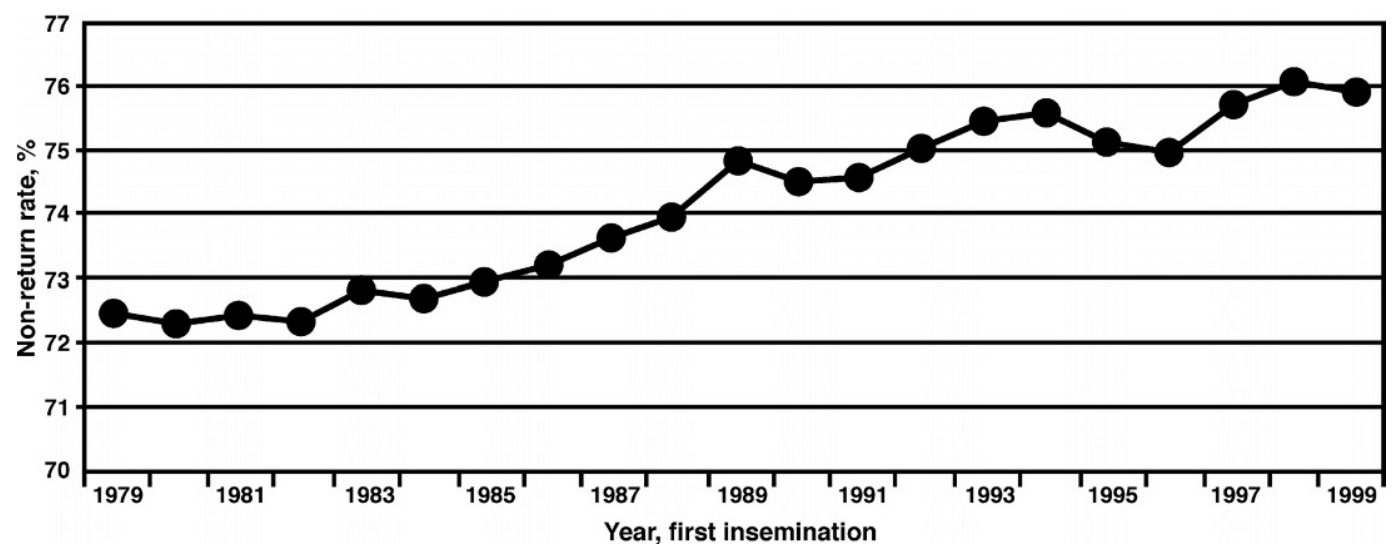

Figure 2. Phenotypic yearly averages of 56-d nonreturn rate in NRF heifers. 


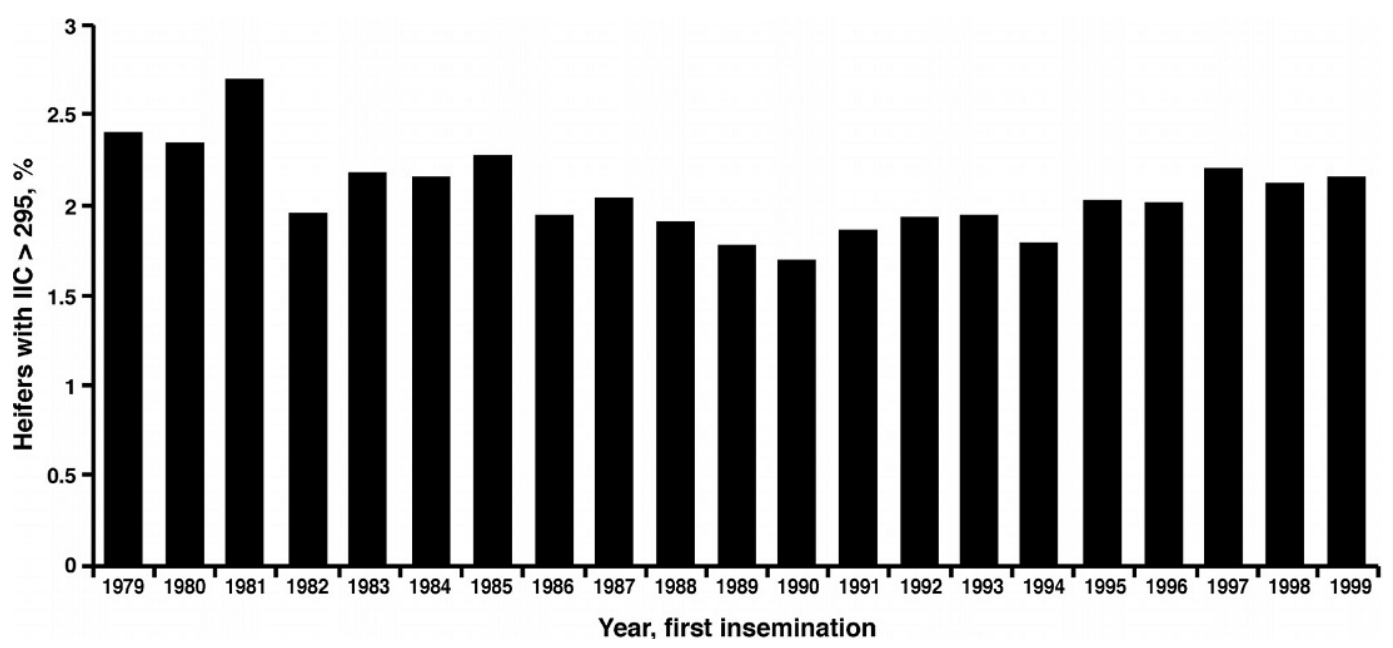

Figure 3. Annual percentage of heifers with more than a 295-d interval from first insemination to calving (IIC) among heifers with a single insemination reported.

$$
\begin{gathered}
\text { hy } \sim \mathrm{N}\left(0, \mathbf{I} \sigma_{\mathrm{hy}}^{2}\right), \mathrm{s} \sim \mathrm{N}\left(0, \mathbf{A} \sigma_{\mathrm{s}}^{2}\right), \mathrm{ss} \sim \mathrm{N}\left(0, \mathbf{A} \sigma_{\mathrm{ss}}^{2}\right) \\
\text { and } \mathrm{e} \sim \mathrm{N}\left(0, \mathbf{I} \sigma_{\mathrm{e}}^{2}\right)
\end{gathered}
$$

where $\sigma_{\mathrm{hy}}^{2}, \sigma_{\mathrm{s}}^{2}, \sigma_{\mathrm{ss}}^{2}$, and $\sigma_{\mathrm{e}}^{2}$ were variance components for effects of herd-year, sire of heifer, service sire, and residual, respectively. A was the additive relationship matrix, and I was the identity matrix. In the models including service sire, the random effects of sire and service sire were assumed to be correlated with the common additive relationship matrix $\mathbf{A}$. The following expectations were assumed for the (co)variances of sire of heifer and service sire effects (Willham, 1963; Van Vleck, 1978):

$$
\begin{gathered}
\mathrm{E}\left(\sigma_{\mathrm{s}}^{2}\right)=1 / 16 \sigma_{\mathrm{d}}^{2}+1 / 4 \sigma_{\mathrm{m}}^{2}+1 / 4 \sigma_{\mathrm{d}, \mathrm{m}} \\
\mathrm{E}\left(\sigma_{\mathrm{ss}}^{2}\right)=1 / 4 \sigma_{\mathrm{d}}^{2} \text { and } \mathrm{E}\left(\sigma_{\mathrm{s}, \mathrm{ss}}\right)=1 / 8 \sigma_{\mathrm{d}}^{2}+1 / 4 \sigma_{\mathrm{d}, \mathrm{m}}
\end{gathered}
$$

These were used to solve additive direct $\left(\sigma_{\mathrm{d}}^{2}\right)$, additive maternal $\left(\sigma_{\mathrm{m}}^{2}\right)$ variance and their covariance $\left(\sigma_{\mathrm{d}, \mathrm{m}}\right)$ components. REML estimates of the (co)variance components were obtained using the VCE4 program (Neumaier and Groeneveld, 1998). The PTAs, given the estimated (co)variance components, were calculated using iteration on data routines in the DMU package (Jensen and Madsen, 1994).

\section{Model Validation}

Validating estimates of genetic trend. A method described by Boichard et al. (1995) was used to validate the six models. In this method, one assumes that successive evaluations of a sire have the same expectation, equal to the true breeding value, and display only ran- dom variation associated with new information. Five data sets were created by restricting year of first insemination from 1978 to 1981, 1985, 1989, 1993, and 1997, respectively. Successive sire evaluations were carried out with increasing amounts of information.

To test for bias in genetic change, the following regression model was used (Boichard et al., 1995):

$$
\mathbf{v}=\mathbf{X g}+\mathbf{u b}+\mathbf{t} \delta+\mathbf{e}
$$

where

$\mathbf{u}, \mathbf{v}=$ vectors of sire evaluations from two releases, $\mathbf{u}$ is estimated with data of daughters in the first period and $\mathbf{v}$ depends both on the data used for $\mathbf{u}$ and on subsequent data;

$\mathbf{g}=$ effect of birth year of sire with incidence matrix $\mathbf{X}$

$\mathrm{b}=$ coefficient, variability changes between methods, here $b=1$;

$\mathbf{t}=$ known vector based on the number of additional daughters each year;

$\delta=$ bias in the estimate of annual genetic trend; and

$\mathbf{e}=$ random error term, with $\mathbf{e} \sim \mathrm{N}\left(0, \mathbf{W}^{-1} \sigma_{\mathrm{e}}^{2}\right)$ and $\mathrm{W}$ as a weighting matrix.

Weights and $\mathbf{t}$ were calculated as described by Boichard et al. (1995). A total of 303 sires in 1981, 801 sires in 1985, 1335 sires in 1989 and 1861 sires in 1993 were included in the weighted regression analyses.

Goodness of fit and predictive ability. The six models were compared according to their ability to predict randomly excluded observations. From herd-year 
Table 3. Variance components and heritability $\left(\mathrm{h}^{2}\right)$ estimates for 56-d nonreturn rate (NR56D0) in heifers, for six models ${ }^{1}$.

\begin{tabular}{|c|c|c|c|c|c|c|}
\hline & Model 1 & Model 2 & Model 3 & Model 4 & Model 5 & Model 6 \\
\hline Service sire variance $\left(\sigma_{\mathrm{ss}}^{2}\right)^{2}$ & $4.806 \times 10^{-4}$ & $4.303 \times 10^{-4}$ & $4.599 \times 10^{-4}$ & & & \\
\hline $\begin{array}{l}\text { Residual variance }\left(\sigma_{\mathrm{e}}^{2}\right)^{2} \\
\text { Total variance }\end{array}$ & $\begin{array}{l}1.837 \times 10^{-1} \\
1.888 \times 10^{-1}\end{array}$ & $\begin{array}{l}1.838 \times 10^{-1} \\
1.848 \times 10^{-1}\end{array}$ & $\begin{array}{l}1.837 \times 10^{-1} \\
1.887 \times 10^{-1}\end{array}$ & $\begin{array}{l}1.840 \times 10^{-1} \\
1.886 \times 10^{-1}\end{array}$ & $\begin{array}{l}1.841 \times 10^{-1} \\
1.846 \times 10^{-1}\end{array}$ & $\begin{array}{l}1.839 \times 10^{-1} \\
1.885 \times 10^{-1}\end{array}$ \\
\hline $\begin{array}{l}\mathrm{h}^{2}=\left(4 \sigma_{\mathrm{s}}^{2} / \text { total variance }\right) \\
\text { Correlation sire and service sire }\left(\mathrm{r}_{\mathrm{s}, \mathrm{ss}}\right)\end{array}$ & $\begin{array}{l}0.013 \\
0.257\end{array}$ & $\begin{array}{l}0.012 \\
0.203\end{array}$ & $\begin{array}{l}0.012 \\
0.229\end{array}$ & 0.014 & 0.012 & 0.012 \\
\hline Maternal additive $\mathrm{h}^{2}=\left(\sigma_{\mathrm{m}}^{2} / \text { total variance }\right)^{4}$ & 0.012 & 0.012 & 0.012 & & & \\
\hline
\end{tabular}

${ }^{1}$ Model 1 with fixed effects of age at first insemination, month of first insemination and double insemination, and random effects of herdyear, sire, service sire and error. Model 2 was equal to Model 1, but with herd-year as fixed effect and Model 3 as Model 1, with monthyear (fixed) replacing month of first insemination. Models 4, 5 and 6 corresponded to models 1,2 and 3 but with the effect of service sire omitted.

${ }^{2}$ Standard error of the ratios (variance component/total variance) $<0.001$.

${ }^{3}$ Direct additive variance: $\sigma_{\mathrm{d}}^{2}=4 \sigma_{\mathrm{ss}}^{2}$.

${ }^{4}$ Cov. between additive direct and additive maternal: $\sigma_{\mathrm{d}, \mathrm{m}}=4 \mathrm{r}_{\mathrm{s}, \mathrm{ss}} \sigma_{\mathrm{s}} \sigma_{\mathrm{ss}}-\frac{1}{2} \sigma_{\mathrm{d}}^{2}$, Maternal additive variance: $\sigma_{\mathrm{m}}^{2}=4 \sigma_{\mathrm{s}}^{2}-\sigma_{\mathrm{d}, \mathrm{m}}-\frac{1}{4} \sigma_{\mathrm{d}}^{2}$.

groups containing more than 2 heifers, 10,000 records were excluded at random. New (co)variance components and new solutions of effects for each of six models were re-estimated using the dataset without the 10,000 records. The predicted $(\hat{y})$ values for the 10,000 records were estimated by using solutions for the different effects in the models. The observed (y) had the value 1 or 0 (NR56D0). The statistics of mean square error (MSE) and the correlation $\left(\mathrm{r}_{\hat{y}, \mathrm{y}}\right)$ between y and $\hat{\mathrm{y}}$ were used to evaluate the models:

$\operatorname{MSE}=\frac{1}{10,000} \sum_{\mathrm{i}=1}^{10,000}\left(\hat{\mathrm{y}}_{\mathrm{i}}-\mathrm{y}_{\mathrm{i}}\right)^{2}$ and $\mathrm{r}_{\hat{\mathrm{y}}, \mathrm{y}}=\frac{\operatorname{cov}(\hat{\mathrm{y}}, \mathrm{y})}{\sqrt{\operatorname{var}(\hat{\mathrm{y}}) \operatorname{var}(\mathrm{y})}}$.

\section{RESULTS}

The REML estimates of variance components and heritability of NR56D0 from the six models are in Table 3. Models 2, 3, 5 and 6 resulted in heritability estimates of $1.2 \%$, while models 1 and 4 with herd-year as random gave slightly larger estimates; $1.3 \%$ and $1.4 \%$, respectively. In the three models including service sire, the direct additive heritability was $0.9 \%$ in Model 2 and $1.0 \%$ in models 1 and 3 , whereas the maternal additive heritability was $1.2 \%$. The genetic correlations between sire and service sire effects were between 0.203 and 0.257 .

Annual average PTAs of the sires were used to describe genetic change in NR56D0 of the heifer population (Figure 4). A linear regression analysis of PTAs of sires on year of first insemination of daughters showed annual genetic change in NR56D0 between $0.15 \%$ (Model 4, $P<0.01$ ) and $0.02 \%$ (models 2 and $5, P<$ 0.01 ). Models 1 and 4, with herd-year treated as random and without any fixed effect of year, showed the steepest positive trend. Estimated genetic changes from the other four models were similar, but the curves were flatter. Results from the model evaluation using the method described by Boichard et al. (1995) are shown in Table 4. None of the models showed significant bias $(P<0.01)$ in any of the four periods. This validation approved all six models for estimation of genetic change.

There were small differences in variance components and estimates of genetic change between the models including service sire (models 1,2 , and 3 ) and the corresponding models without service sire (models 4,5 , and 6). As shown in Table 5, there was no difference between models with and without service sire in MSE or correlation between observed and predicted values. Models 2 and 5 including fixed herd-year effect, showed higher prediction error and a lower correlation between observed and predicted values than the other models.

Effects of month-year of first insemination and age at first insemination from Model 6 are shown in Figure 5 and Figure 6, respectively. Figure 5 depicts the period from January 1980 to January 1986 and the pattern was similar over the entire period. The solutions for month-year showed highest values in the summer season and lowest values in the winter season. NR56D0 increased linearly with age at first insemination in the interval 12.2 mo to 24.6 mo as shown in Figure 6. This age interval included $96 \%$ of the heifers. The contrast between the two classes for double insemination was $0.004(\mathrm{SE}=0.001)$, and the class with double insemination had the largest value.

\section{DISCUSSION}

The Norwegian Dairy Herd Recording System contains all AI-data combined with calving and production 
Table 4. Estimated bias in annual genetic change of 56-d nonreturn rate from regression analysis of sires, estimated breeding values on the same sire, breeding values estimated at an earlier stage, for the six models.

\begin{tabular}{|c|c|c|c|c|c|}
\hline \multirow[b]{3}{*}{ Model $^{1}$} & \multicolumn{2}{|c|}{ Evaluation as } & \multirow{2}{*}{\multicolumn{3}{|c|}{ Bias }} \\
\hline & & & & & \\
\hline & variable & variable & Estimate & SE & $\mathrm{P}^{2}$ \\
\hline \multirow[t]{4}{*}{ Model 1} & 1985 & 1981 & -0.00076 & 0.00470 & 0.87 \\
\hline & 1989 & 1985 & 0.00097 & 0.00646 & 0.88 \\
\hline & 1993 & 1989 & -0.00039 & 0.00420 & 0.93 \\
\hline & 1997 & 1993 & 0.00185 & 0.00277 & 0.50 \\
\hline \multirow[t]{4}{*}{ Model 2} & 1985 & 1981 & -0.00147 & 0.00582 & 0.80 \\
\hline & 1989 & 1985 & 0.00044 & 0.00838 & 0.96 \\
\hline & 1993 & 1989 & -0.00222 & 0.00435 & 0.61 \\
\hline & 1997 & 1993 & 0.00190 & 0.00306 & 0.53 \\
\hline \multirow[t]{4}{*}{ Model 3} & 1985 & 1981 & 0.00030 & 0.00484 & 0.95 \\
\hline & 1989 & 1985 & 0.00057 & 0.00688 & 0.93 \\
\hline & 1993 & 1989 & -0.00244 & 0.00382 & 0.52 \\
\hline & 1997 & 1993 & 0.00117 & 0.00258 & 0.65 \\
\hline \multirow[t]{4}{*}{ Model 4} & 1985 & 1981 & -0.00093 & 0.00451 & 0.84 \\
\hline & 1989 & 1985 & 0.00219 & 0.00605 & 0.72 \\
\hline & 1993 & 1989 & 0.00179 & 0.00466 & 0.70 \\
\hline & 1997 & 1993 & 0.00230 & 0.00298 & 0.44 \\
\hline \multirow[t]{4}{*}{ Model 5} & 1985 & 1981 & -0.00102 & 0.00591 & 0.86 \\
\hline & 1989 & 1985 & -0.00012 & 0.00862 & 0.99 \\
\hline & 1993 & 1989 & -0.00222 & 0.00437 & 0.61 \\
\hline & 1997 & 1993 & 0.00191 & 0.00307 & 0.53 \\
\hline \multirow[t]{4}{*}{ Model 6} & 1985 & 1981 & 0.00021 & 0.00490 & 0.97 \\
\hline & 1989 & 1985 & 0.00066 & 0.00693 & 0.92 \\
\hline & 1993 & 1989 & -0.00230 & 0.00387 & 0.55 \\
\hline & 1997 & 1993 & 0.00127 & 0.00261 & 0.63 \\
\hline
\end{tabular}

${ }^{1}$ Model 1 with fixed effects of age at first insemination, month of first insemination, and double insemination and; random effects of herd-year, sire, service sire and error. Model 2 was equal to Model 1, but with herdyear was as fixed and Model 3 as Model 1, but with month-year (fixed) replacing month of first insemination. Models 4, 5 and 6 corresponded to models 1, 2 and 3 but effect of service sire omitted.

${ }^{2}$ For hypothesis, bias estimate $=0$.

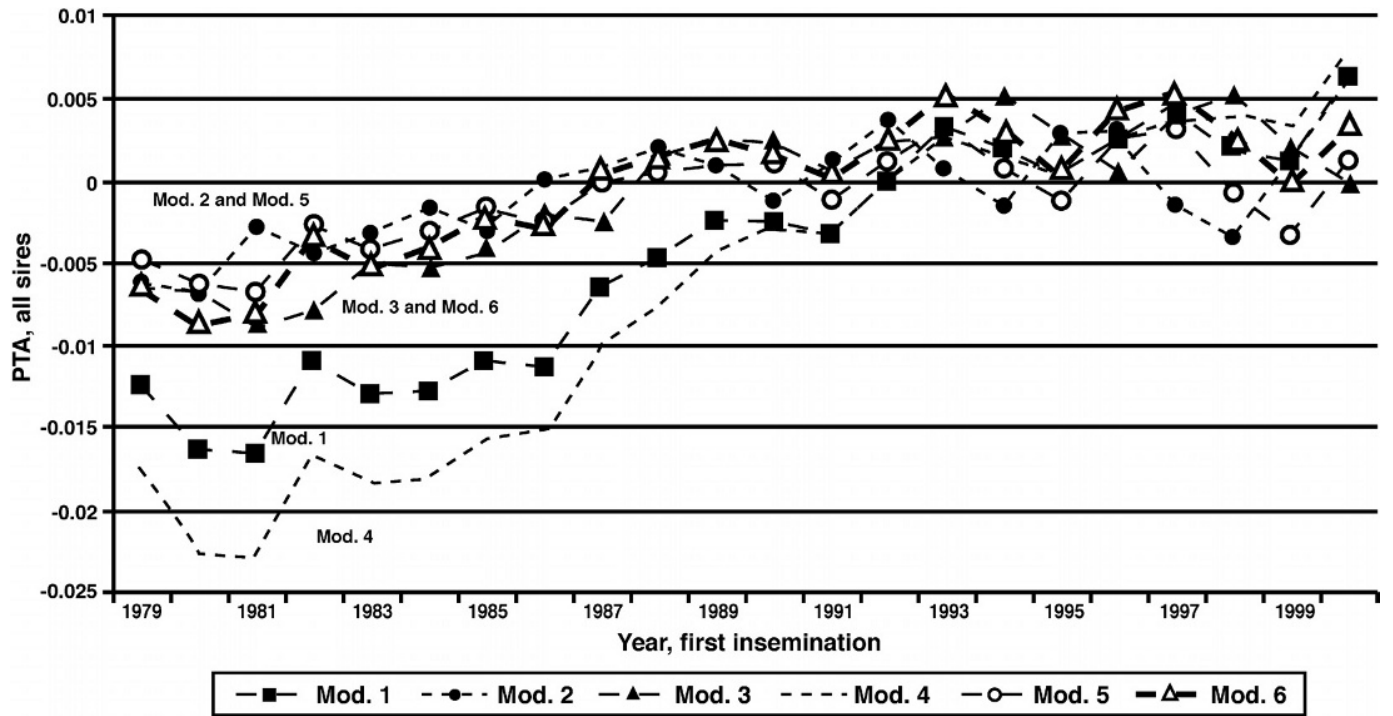

Figure 4. Genetic change of 56-d nonreturn (NR56D0) in virgin heifers, shown as mean PTAs of sires by year of first inseminations for daughters. Model 1 with fixed effects of age at first insemination, month of first insemination and double insemination and random effects of herd-year, sire, service sire, and error. Model 2 was as Model 1, but with herd-year as fixed effect and Model 3 was as Model 1 with month-year (fixed) replacing month of first insemination. Models 4, 5 and 6 corresponded to models 1, 2, and 3 with effect of service sire omitted. 
Table 5. Mean squared error (MSE) and correlation ( $r$ ) between observed and predicted values for six models $^{1}$

\begin{tabular}{lllllll}
\hline Model & Model 1 & Model 2 & Model 3 & Model 4 & Model 5 & Model 6 \\
\hline MSE & 0.189 & 0.227 & 0.189 & 0.189 & 0.227 & 0.189 \\
$\mathrm{r}$ & 0.108 & 0.066 & 0.107 & 0.108 & 0.065 & 0.107 \\
\hline
\end{tabular}

${ }^{1}$ Model 1 with fixed effects of age at first insemination, month of first insemination, and double insemination and; random effects of herd-year, sire, service sire and error. Model 2 was equal to Model 1, but with herdyear as fixed and Model 3 as Model 1, but with month-year (fixed) replacing month of first insemination. Models 4, 5 and 6 corresponded to models 1,2 and 3 but effect of service sire omitted.

information for a period of more than twenty years. Whether nonreturn is a useful trait to measure fertility depends on the quality of the reporting of inseminations and mating. Changes in reporting routines can be a problem when estimating genetic change. However, this study showed that the proportion of NRF heifers with prolonged interval from first insemination to calving was nearly constant from 1979 to 1999 . Phenotypically, NR56D0 increased 3.4\% units during the same period (Figure 2). From 1972 to 2000 the selection criteria for fertility in NRF has been NR56D0, and the weight in the total merit index has increased from $8 \%$ to $15 \%$ during this period.

The REML estimates of variance components from the six models were all small, and heritabilities varied from $1.2 \%$ to $1.4 \%$. This is in agreement with Pedersen and Jensen (1996) and Hodel et al. (1995), who found heritability estimates of $0.8 \%$ and $1.1 \%$ for 56 and 90 $\mathrm{d}$ nonreturn rate in heifers, respectively. The three models including service sire allowed estimation of di- rect additive heritabilities $(0.9-1.0 \%)$ and maternal additive hertitabilities (1.2\%). The direct effect includes viability of the embryo and the effect of sperm quality, while the uterine environment, egg quality, and embryo vitality are effects in the maternal component of variance. Using a model including the effect of service sire and a similar (co)variance structure for $60 \mathrm{~d}$ nonreturn in heifers, Jansen (1986) found that the additive direct heritabilities were slightly larger (0.021) and the additive maternal heritabilities slightly smaller $(0.007)$ than in the present study. The genetic correlation between sire and service sire (0.203 to 0.257) deviated from those of Jansen (1986), where the correlation was -0.290 , and also from the genetic correlation between sire and service sire effects of -0.11 reported by Boichard and Manfredi (1994). This lack of consistency may be explained by standardization of frozen semen, which reduces service sire variance and also affects the covariance between sire and service sire effects. As discussed in Jansen (1986), different semen processing could in-

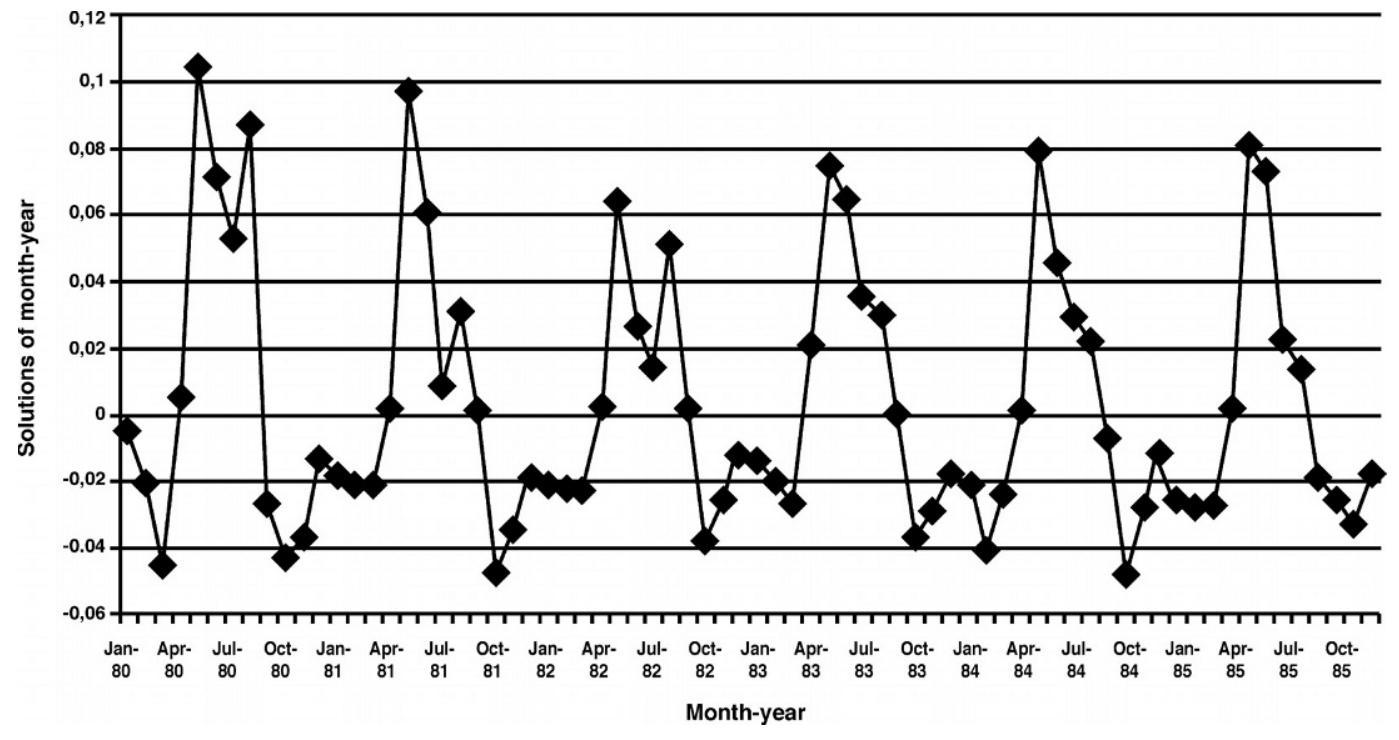

Figure 5. Solutions of month-year effect for 56-d nonreturn rate in NRF heifers in the period from January 1980 to January 1986 , from Model 6, with fixed effects of age at first insemination, month-year of first insemination and double insemination, and random effects of herd-year, and error. 


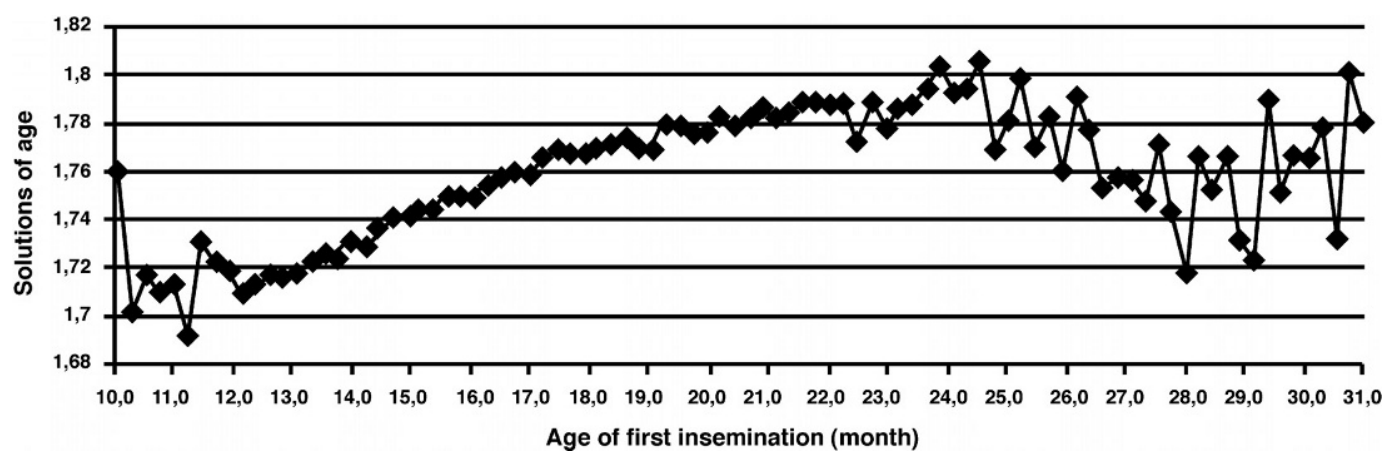

Figure 6. Solutions of age at first insemination effect for 56-d nonreturn rate in NRF heifers, from Model 6, with fixed effects of age at first insemination, month-year at first insemination and double insemination, and random effects of herd-year, and error.

fluence the result of nonreturn rates in service sires. Kommisrud et al. (1996) found a difference of $1.2 \%(P$ $<0.01)$ in 60 -d nonreturn between two different semen extenders.

In all six models, genetic change was positive with the steepest gradient obtained from models 1 and 4 . Although the models resulted in different trends (Figure 4), the model validation (Table 3 ) did not reveal significant bias for any period. The method used was not able to detect bias in the evaluated models. This could be due to very small heritabilities, lack of bias, or both. The differences between breeding values estimated with a large group of first crop daughters and breeding values estimated with additional information from second crop daughters on the same sire were quite small.

Models 1, 3, 4, and 6 containing random herd-year effect, showed smaller MSE and higher correlation between observed and predicted values (Table 5) than Model 2 and 5, which treated herd-year as fixed. This is due to small herd sizes in Norway, and because treating herd-year as random leads to improved utilization of the information compared to models with a fixed herdyear effect. Henderson (1973) and Ugarte (1992) both recommend modeling herd-year as fixed when sires are used nonrandomly over herds. However, semen of each $\mathrm{NRF}$ test sire is distributed and used at random throughout Norway. The use of elite sires in each herd is regulated, based on herd size and semen availability of the sire. Only a few doses of the highest ranking sires can be used in each herd. Therefore no bias from nonrandom use of sires across herds in this data should exist.

Similar needs as those reported by Henderson (1973) for separating additive breeding values from environmental effects exist when data are available over a long time span. Heringstad et al. (1999b) compared models with fixed versus random contemporary group effects in an analysis of clinical mastitis and concluded that the model must include a fixed structure to be able to separate environmental trend from genetic change. In this study, solutions of month-year with Model 6 resulted in different values for the same month between year (Figure 5).

Although, models with service sire are nearer the true biological situation, the goodness-of-fit and predictive ability were not improved in models with service sire included compared to corresponding models without service sire (Table 5). Models 4 and 6 showed almost equal validation results for goodness-of-fit and predictive ability. Because Model 6 includes effects for month-year of insemination while Model 4 includes only month of insemination, Model 6 is preferred irrespective of equal validation results for goodness-of-fit and predictive ability.

NR56D0 was analyzed with a linear sire model, although a threshold model would have been more appropriate for categorical data (Gianola, 1982). However, in view of the large daughter groups, making averages of $0-1$ records close to normally distributed. Linear models have been shown to work well when binomal probabilities fall within the range of 20 to $80 \%$ (Van Vleck, 1971). The rank correlation between EBVs from linear and threshold models should therefore be high, as estimated by Weller and Ron (1992) for conception rate (> 0.99). Estimates of genetic change have been found slightly larger for threshold models (Heringstad et al., 2002), making results from a linear model more conservative.

\section{CONCLUSIONS}

This is the first genetic analysis of female fertility in virgin heifers including more than 1.6 million records over a period of $20 \mathrm{yr}$. Six linear sire models gave small heritabilities, from $1.2 \%$ to $1.4 \%$ and estimated genetic improvement for NR56D0 in NRF from 1978 to 2000. Despite somewhat different estimates of genetic 
change, the model validation procedure of Boichard et al. (1995) was not able to detect bias in genetic change for any of the six models. The presence or absence of service sire in the models had a small effect on both variance component estimates, model validation and genetic change. The ability to predict randomly excluded observations was better when modelling herdyear as a random effect. However, to avoid confounding environmental and genetic effects, the evaluation model should also contain a fixed season-year effect. In $\mathrm{NRF}$, the favourable genetic change is a result of progeny testing, utilizing large progeny groups and a high relative weight on fertility in the total merit index for sires.

\section{ACKNOWLEDGMENTS}

Access to the data was granted in the agreement number 005.2000 by the Norwegian Dairy Herd Recording System on February 24, 2000. GENO Breeding and AI Association is acknowledged for providing pedigree information on sires.

\section{REFERENCES}

Boichard, D., B. Bonaiti, A. Barbat, and S. Mattalia. 1995. Three methods to validate the estimation of genetic trend for dairy cattle. J. Dairy Sci. 78:431-437.

Boichard, D., and E. Manfredi. 1994. Genetic Analysis of Conception Rate in French Holstein Cattle. Acta. Agric. Scand. 44:138-145. GENO. 2002. Annual report 2001. Hamar, Norway.

Gianola, D. 1982. Theory and analysis of threshold characters. J. Anim. Sci. 54:1079-1096.

Hansen, L. B., A. E. Freeman, and P. J. Berger. 1983. Yield and Fertility Relationships in Dairy Cattle. J. Dairy Sci. 66:293-305.

Henderson, C. R. 1973. Sire evaluation and genetic trends. Pages 10-41 in Proc. Anim. Breeding Genet. Symp. In Honor of Dr. J. L. Lush, ASAS, ADSA, Champaign, IL.

Heringstad, B., G. Klemetsdal, and J. Ruane. 1999a. Clinical Mastitis in Norwegian Cattle: Frequency, Variance Components, and Genetic Correlation with Protein Yield. J. Dairy Sci. 82:1325-1330.

Heringstad, B., G. Klemetsdal, and J. Ruane. 1999b. Short Communication: Validation of Estimates of Genetic Trend in the Norwegian Cattle Population. J. Dairy Sci. 82:2811-2812.

Heringstad, B., R. Rekaya, D. Gianola, G. Klemetsdal, and K. A. Weigel. 2003. Genetic change for clinical mastitis in Norwegian Cattle: a threshold model analysis. J. Dairy Sci. 86:369-375.
Hodel, F., J. Moll, and N. Kuenzi. 1995. Analysis of fertility in Swiss Simmental cattle-Genetic and environmental effects on female fertility. Livest. Prod. Sci. 41:95-103.

Hoekstra, J., A. W. van der Lugt, J. H. J. van der Werf, and W. Ouweltjes. 1994. Genetic and phenotypic parameters for milk production and fertility traits in upgraded dairy cattle. Livest. Prod. Sci. 40:225-232.

Jansen, J. 1986. Direct and maternal, genetic parameters of fertility traits in Friesian cattle. Livest. Prod. Sci. 15:153-164.

Janson, L., and B. Andreasson. 1981. Studies on Fertility Traits in Swedish Dairy Cattle. IV:Genetic and Phenotypic Correlation Between Milk Yield and Fertility. Acta Agric. Scand. 31:313-322.

Jensen, J., and P. Madsen. 1994. DMU: A package for the analysis of multivariate mixed models. Proc. 5th World Congr. Genet. Appl. Livest. Prod. Guelph, Canada. Comput. Stat. Software $22: 45-46$.

Kommisrud, E., T. Graffer, and T. Steine. 1996. Comparison of two processing systems for bull semen with regard to post-thaw motility and nonreturn rates. Theriogenol. 45:1515-1521.

Lindhé, B., and J. Philipsson. 2001. Genetic trends in the two Swedish dairy cattle breeds SRB and SLB in 1985-1999. Publ. No. 138. Swedish Univ. of Agric. Sci., Dept. Anim. Breed Genet., SE-75007 Uppsala, Sweden.

Lyons, D. T., and A. E. Freeman. 1991. Genetics of Health Traits in Holstein Cattle. J. Dairy Sci. 74:1092-1100.

Neumaier, A., and E. Groeneveld. 1998. Restricted maximum Likelihood estimation of covariances in sparse linear models. Genet. Sel. Evol. 30:3-26.

Pedersen, J., and J. Jensen. 1996. Evaluation of Female fertility of Danish Dairy Sires. Pages 72-77 in Proc. Int. Workshop on Genetic Improvement of Functional Traits in Cattle. Gembloux, Belgium, January 1996. INTERBULL Bull. no. 12, Int. Bull. Eval. Serv., Uppsala, Sweden.

Roxström, A., E. Strandberg, B. Berglund, and U. Emanuelson. 2001. Genetic and Environmental Correlations Among Female Fertility Traits and Milk Production in Different Parities of Swedish Red and White Dairy Cattle. Acta. Agric. Scand. 51:7-14.

TINE. 2002. Annual report 2001. Ås, 98pp. (In Norwegian, with English tables).

Ugarte, E., R. Alenda, and M. J. Carabaño. 1992. Fixed or Random Contemporary Groups in Genetic Evaluations. J. Dairy Sci. 75:269-278.

Van Vleck, L. D. 1971. Estimation of Heritability of Threshold Characters. J. Dairy Sci. 55: 218-225.

Van Vleck, L. D. 1978. A Genetic Model Involving Fetal Effects on Traits of the Dam. Biomet. 34:123-127.

Weigel, K. A., and R. Rekaya. 2000. Genetic Parameters for Reproductive Traits of Holstein Cattle in California and Minnesota. J. Dairy Sci. 83:1072-1080.

Weller, J. I., and E. Ezra. 1997. Genetic Analysis of Somatic Cell Score and Female Fertility of Israeli Holsteins with an Individual Animal Model. J. Dairy Sci. 80:586-593.

Weller, J. I., and M. Ron. 1992. Genetic analysis of fertility traits in Israeli Holsteins by linear and threshold models. J. Dairy Sci. 75:2541-2548.

Wilham, R. L. 1963. The covariance between relatives for characters composed of components contributed by related individuals. Biomet. 19:18-27. 